\title{
Study on Openness of Chinese Stock Market: Comparing with Mature Markets
}

\author{
Yu Zhao, Yu Zhang and Chunjie Qi
}

\begin{abstract}
The maturity and openness of Chinese stock markets can be measured by price impact of other mature stock markets on them. The article uses wavelet analysis to eliminate noise in stock price signal and analyzes to what degree is Shanghai stock market affected by volatility of stock markets of Hong Kong, Tokyo, New York and London by using SVAR (Structural Vector Auto Regression), impulse response analysis and variance decomposition. The results show that Chinese stock markets are becoming more and more mature and open, which are integrated into the global stock market gradually, which can be known from the response of Shanghai Composite Index shocked by the other indices. Among all the mature stock indices in the paper, influence of Dow-Jones Index on Shanghai Composite Index is most significant, followed by FTSE100 Index.
\end{abstract}

Index Terms - Chinese Stock Markets, Wavelet Analysis, SVAR; Impulse Response, Variance Decomposition.

\section{INTRODUCTION}

The development of Chinese capital market is relatively backward and closed. The interaction of stock markets at home and abroad was not obvious in the beginning of the 1990s. As our ability to maintain balance of payments is improving and domestic enterprises are accelerating their oversea listing financing, at present, western academic circles start to pay attention to the openness of Chinese stock market and its connection with foreign stock market. A lot of researches show that there is no significant dependency relation between Chinese and international stock market in the earlier days of Chinese stock market (Bailey, 1994; Johnson, Sun and Soenen, 1994; Huang, Yang and Hu, 2000) [1], [2], [3]. Through observing stock markets of eight East Asian countries during 1995-1998, Tan (1998) confirmed the "contagion effect" of Southeast Asian financial crisis in Asian market by using Vector Error Correction Model [4].

Manuscript received September 5, 2009. This work was supported in part by the Program of Science and Technology Innovation Team of distinguished youth of colleges and universities in Hubei province (Project Number: T200813), People's Republic of China.

Zhao Yu was with the College of Economics \& Management, Huazhong Agricultural University, Wuhan, 430070, China. He is now with the College of Economics \& Management, ECIT, Nanchang, 330013, China. (*Corresponding author: 86-0-13114360203; fax: 86-027-87276077; e-mail: math052360@gmail.com).

Zhang Yu is with the College of Economics \& Management, Huazhong Agricultural University, Wuhan, Hubei, 430070, China (e-mail: zyzyonly@126.com).

Qi Chunjie is with the College of Economics \& Management, Huazhong Agricultural University, Wuhan, Hubei, 430070, China (e-mail: qichunjie@mail.hzau.edu.cn).
Chang (2001) found that financial crisis had a noticeable impact in American stock market by comparing with stock markets of Taiwan, Hong Kong, Japan and THE USA during 1997-1998 [5].

The paper is aimed to understand the openness of Chinese stock market. The article uses wavelet analysis to eliminate noise in stock price signal firstly, and then applies SVAR (Structural Vector Auto Regression), impulse response function and variance decomposition to simulate impacts of Shanghai stock market affected by volatility of other stock markets at home and abroad. The dynamic inter-linkages between Chinese stock market and other markets of developed countries reflect openness of Chinese stock market.

The paper is organized into five sections. Section II provides a brief overview of empirical literature on interlinkages and interaction of stock markets. Section III describes methodology adopted in the study. Section IV gives data used in the paper. Section $\mathrm{V}$ discusses the empirical results. Section VI concludes the results.

\section{LITERATURE REVIEW}

Roca (1999) investigated the interlinkages among equity markets of Japan, Korea, U.S, U.K., Singapore, Taiwan, Australia and Hong Kong by employing Granger causality test and Johansen cointegration technique. His results revealed that no cointegration exists between Australia and other markets but Australian market was found significantly influenced by U.S. and U.K. markets [6].

Andrew C.Worthington, Masaki Katsuura and Helen Higgs (2003) examined price linkages among Asian equity markets in the period surrounding the Asian economic, financial and currency crises. Three developed markets (Hong Kong, Japan and Singapore) and six emerging markets (Indonesia, Korea, Malaysia, the Philippines, Taiwan and Thailand) were included in the analysis. They used Multivariate cointegration and level VAR procedures to examine causal linkages among these markets. The results indicated that there was a stationary relationship and significant causal linkages between the Asian equity markets and lower causal relationships that existed between the developed and emerging equity markets suggested that opportunities for international portfolio diversification in Asian equity markets still exist [7].

S. Edwards, Biscarri and Gracia (2003) analyzed the behavior of stock markets in six emerging countries. More specifically, they described the bull and bear cycles of four Latin American and two Asian countries, comparing their 
characteristics during both phases and the degree of concordance of bullish periods. They divided the sample in two subperiods in order to account for differences induced by the financial liberalization processes that these countries went through in the early 1990s. They found that cycles in emerging countries tended to have shorter duration and larger amplitude and volatility than these in developed countries. However, after financial liberalization Latin American stock markets had behaved more similarly to stock markets in developed countries whereas Asian countries had become more dissimilar [8].

Wang and Pan (2004) studied the interlinkage between the S\&P 500 index and Shanghai composite index using multiresolution analysis. Their results showed that the volatility spillover effects did not exist from the S\&P 500 index to Shanghai composite index, and Shanghai stock market seemed to be independence [9].

K. M. Wang and Thanh-Binh Nguyen Thi (2006) tested whether contagion effects exist, during the "Asian flu", between the stock markets of Thailand and the Chinese economic area. They found that the stock markets displayed a significant increase in the means of correlation coefficients across markets between the pre-crisis and post-crisis periods and proved the existence of contagion between the studied markets [10].

Abdulnasser, Eduardo Roca and Daniel Buncic (2006) analyzed the causal relationship between the equity markets of the US and those of the UK, Japan, Germany, France, Canada and Australia based on leveraged bootstrap approach which overcame problems of non-normalities and $\mathrm{ARCH}$ effects in the data. Their results implied that after September 11 , the other markets became more efficient in responding to information transmitted from the US market [11].

Hasan, Saleem and Abdullah (2008) examined the long term relationship between Karachi stock exchange and equity markets of developed world for the period from 2000 to 2006 by using multivariate Cointegration analysis. Johansen and Juselius multivariate Cointegration analysis indicated that markets were integrated and there existed a long term relationship between these markets. However pair wise Cointegration analysis showed that Karachi stock market was not cointegrated with equity market of US, UK, Germany, Canada, Italy and Australia [12].

Numerous studies have tested the relationships among international stock markets, however, most of these studies focused on mature stock market. Chinese stock market now is one of the largest equity markets by market capitalization, so a comprehensive study to explore the interlinkages between Chinese emerging markets and other mature markets is significative.

In addition, there is a good deal of noise in financial time series which makes the estimated result and simulation more ambiguous and less accurate. When modeling with financial time series, combining wavelet analysis with traditional econometric model can eliminate noise in series and improve precision of the model [13], [14].

\section{RESEARCH METHOD}

Basic hypothesis:

(i) Both variable process $x_{t}$ and $y_{t}$ are stationary random process.

(ii) Random error series $u_{x t}$ and $u_{y t}$ are white noise series $\sigma_{u_{x}}^{2}=\sigma_{u_{y}}^{2}$.

(iii) $u_{x t}$ and $u_{y t}$ are uncorrelated, $\operatorname{cov}\left(u_{x t}, u_{y t}\right)=0$.

Structural Vector Autoregressive model:

$$
\begin{aligned}
& x_{t}=\alpha_{1}+\beta_{10} y_{t}+\ldots \beta_{1 n} y_{t-n}+\gamma_{11} x_{t-1}+\ldots \gamma_{1 m} x_{t-m}+u_{x t} \\
& y_{t}=\alpha_{2}+\beta_{20} x_{t}+\ldots \beta_{2 n} x_{t-n}+\gamma_{21} y_{t-1}+\ldots \gamma_{2 m} y_{t-m}+u_{y t}
\end{aligned}
$$

The article introduced effect and feedback effect among variables. Coefficient $\beta_{10}$ represents the instant effects of unit change of $y_{t}$ on $x_{t}$, in which $\mathrm{y}_{\mathrm{t}}$ and $x_{t}$, are variables. $\gamma_{1 \mathrm{~m}}$ represents lag effect of unit change of $x_{t-m}$ on $x_{t}$. Though $u_{x t}$ and $u_{y t}$ are random shocks that simply appear in the model, if $\beta_{10} \neq 0, \beta_{20} \neq 0$, there will be interactive instant shocks existing in uxt and uyt. Mutual influence of shocks embody bilateral and feedback relationships of variable effect. Considering for $\mathrm{k}$ variables, SVAR of order $\mathrm{p}$ is as following:

$$
\begin{gathered}
B_{0} z_{t}=\Gamma_{1} z_{t-1}+\Gamma_{2} z_{t-2}+\ldots+\Gamma_{p} y_{t-p}+u_{t} \\
B_{0}=\left[\begin{array}{cccc}
1 & -b_{12} & \ldots & -b_{1 k} \\
-b_{21} & 1 & \ldots & -b_{2 k} \\
\ldots & \ldots & \ldots & \ldots \\
-b_{k 1} & -b_{k 2} & \ldots & 1
\end{array}\right] \\
\Gamma_{i}=\left[\begin{array}{cccc}
\gamma_{11}^{(i)} & \gamma_{12}^{(i)} & \ldots & \gamma_{1 k}^{(i)} \\
\gamma_{21}^{(i)} & \gamma_{22}^{(i)} & \ldots & \gamma_{2 k}^{(i)} \\
\ldots & \ldots & \ldots & \ldots \\
\gamma_{k 1}^{(i)} & \gamma_{k 2}^{(i)} & \ldots & \gamma_{k k}^{(i)}
\end{array}\right], u_{t}=\left[\begin{array}{l}
u_{1 t} \\
u_{2 t} \\
\ldots \\
u_{k t}
\end{array}\right]
\end{gathered}
$$

We can write (2) as the form of lag operator, as follows:

$$
\begin{gathered}
B(L) y_{t}=\left(B_{0}-\Gamma_{1} L-\Gamma_{2} L^{2}-\ldots-\Gamma_{p} L^{p}\right) y_{t}=u_{t}, \\
E\left(u_{t} u_{t}^{\prime}\right)=I_{k} .
\end{gathered}
$$

If $B(L)$ is reversible, so

$$
y_{t}=D(L) u_{t}=B(L)^{-1} u_{t}=\left(D_{0}+D_{1} L+\ldots, D_{0}\right) u_{t}=B_{0}^{-1} u_{t}
$$

In model (3), all the endogenous variables are expressed as distributed lags of exogenous variables. $u_{t}$ represents as exogenous variables' structural impact, they can't be gotten from direct observation, and we can only get them through the responses of endogenous variables. The constraint condition, imposing on $\mathrm{D}_{0}$ to recognize SVAR, as follows:

$$
D_{0} D_{0}{ }^{\prime}=G Q G^{\prime}=G Q^{1 / 2} Q^{1 / 2} G^{\prime}=P P^{\prime}
$$

$\mathrm{G}$ denotes a lower triangular matrix that all elements in main diagonal are 1; $\mathrm{Q}$ denotes a diagonal matrix that all elements in main diagonal are positive; $\mathrm{P}$ is a lower triangular matrix. In order to impose constraint, we multiply P-1 simultaneously on both sides of VAR model. 
For SVAR of order $\mathrm{p}$ which has $\mathrm{k}$ variables, we use impulse response as followed:

$$
D_{q}=\frac{\partial y_{t+q}}{\partial u_{t}}, t=1,2 \ldots T
$$

Definite relative variance contribution as:

$$
R V C_{j \rightarrow i}(\infty)=\frac{\sum_{q=0}^{\infty}\left(c_{i j}^{(q)}\right) \sigma_{j j}}{\operatorname{var}\left(y_{i t}\right)}, i, j=1,2 \ldots k
$$

When model (3) meets stationarity, $c_{i j}^{(q)}$ present decreasing of geometric series with the increase of q. So, model (6) is the approximate representation of model (5), as follows:

$$
R V C_{j \rightarrow i}(s)=\frac{\sum_{q=0}^{s-1}\left(c_{i j}^{(q)}\right) \sigma_{j j}}{\operatorname{var}\left(y_{i t}\right)}, i, j=1,2 \ldots k
$$

\section{FILTERING AND DATE PREPROCESSING}

\section{A. Wavelet transformation}

In order to improve parameters precision of SVAR model, we need to use wavelet analysis to eliminate noise in signal.

Assume $\psi(t) \in \mathrm{L}^{2}(\mathrm{R})$, its Fourier transformation is as $\hat{\psi}(\omega)$. When $\hat{\psi}^{(\omega)}$ satisfies admissible condition that as follows,

$$
C_{\Psi}=\int_{R} \frac{|\hat{\psi}(\omega)|^{2}}{\omega} d \omega<\infty
$$

In this case, $\psi(t)$ can be defined as basic wavelet. Deducing from admissible condition, basic wavelet $\psi(t)$ must satisfy $\hat{\psi}(0)=0$ at least, which means that $\int \psi(t) d t=0$. In other words, $\hat{\psi}(\omega)$ must have the characteristic of bandpass filtering.

We call wavelet sequence as daughter wavelet, which are got from contraction-expansion and translation of basic wavelet,

$$
\psi_{a, b}(t)=\frac{1}{\sqrt{|a|}} \psi\left(\frac{t-b}{a}\right)
$$

Where $a, b \in R, a \neq 0, a$ is contraction-expansion factor or scale factor; $b$ is displacement factor.

Wavelet transformation of signal $f(t)$ can be defined as follows,

$$
W_{\psi} f(a, b)=\frac{1}{\sqrt{|a|}} \int_{-\infty}^{+\infty} f(t) \hat{\psi}\left(\frac{t-b}{a}\right) d t
$$

If $\psi(t)$ satisfies admissible condition, signal $f(t)$ can be reconstruction as follows,

$$
f(t)=C_{\psi}^{-1} \iint_{R^{2}} W_{\psi} f(a, b) \psi_{a, b}(t) \frac{d a d b}{a^{2}}
$$

We make continuous wavelet discretization in Matlab 7.0. Let $\mathrm{a}=\mathrm{a}_{0}{ }^{\mathrm{m}}, \mathrm{b}=\mathrm{nb} \mathrm{b}_{0} \mathrm{a}_{0}{ }^{\mathrm{m}}, \mathrm{a}_{0}>1, \mathrm{~b}_{0} \in \mathrm{R}$, and discrete wavelet of signal $f(t)$ is transformed into following form,

$$
W_{\psi} f(m, n)=a_{0}^{-\frac{m}{2}} \int_{-\infty}^{+\infty} f(t) \hat{\psi}\left(a_{0}^{-m} t-n b_{0}\right) d t
$$

While $\mathrm{a}_{0}=2, \mathrm{~b}_{0}=1$, the function above becomes dyadic wavelet transformation,

$$
W_{\psi} f(m, n)=2^{-m} \int_{-\infty}^{+\infty} f(t) \hat{\psi}\left(2^{-m} t-n\right) d t
$$

Sampling step for different frequency components in the time domain is adjustable; sampling stem of high frequency one is small and it corresponds to smaller m; low frequency one is just opposite and corresponds to bigger m. Thereupon, wavelet transformation realized time-frequency localization with fixed window size and variable window shape.

For each $f(t) \in \mathrm{L} 2(\mathrm{R})$ corresponding wavelet series can be got from wavelet $\Psi$, as follows,

$$
f(t)=\sum_{j, k} C_{j, k} \psi_{j, k}(t)
$$

If $\left\{\Psi_{j, k}\right\}$ comprise orthonormal basis, and let $W_{j}=\operatorname{span}<\Psi_{j, k}$, $\mathrm{k} \in \mathrm{zz}>$, which denotes closed space expanding by linear ways of $\Psi_{j, k}$. It's absolutely that the following formula is available.

$$
L^{2}(I R)=\sum_{j \in z} W_{j}=\ldots \oplus W_{-1} \oplus W_{0} \oplus
$$

Accordingly, square integrable signals in every real space have a unique factorization as follows,

$$
f(t)=\sum_{j \in z} g_{j}(t), g_{j}(t) \in W_{j} .
$$

Introducing multi-scale analysis in $\mathrm{Wj}$ on precondition of its direct sum, where $W_{j}$ appears in $L^{2}(I R)$ that we just mentioned above. Letting

$$
V_{j}=W_{j+1}+W_{j+2}+\ldots \quad, j \in z z
$$

If $f(t) \in \mathrm{L}^{2}(\mathrm{R})$ and assume $f(t) \in V_{0}$, then $V_{0}=V_{l}+W_{l}$ and $f(t)=f_{l}(t)+g_{l}(t)$ accordingly; if the decomposition is far from satisfactory, according to $V_{1}=V_{2}+W_{2}$, it must meet the condition $f(t)=f_{2}(t)+g_{2}(t)+g_{1}(t)$. Repeat the process until you feel satisfacted with the results. Finally, $f(t)$ will be denoted as follows,

$$
\begin{gathered}
V_{j}=W_{j+1}+W_{j+2}+\ldots \quad, j \in z z \\
f(t)=f m(t)+g m(t)+\ldots+g l(t) .
\end{gathered}
$$

Daubechies wavelet is one of the wavelets which are the most widely used at present. It is compactly supported orthonormal wavelet and has nice performance. Daubechies wavelet doesn't have definite expression, but square norm of its transfer function can be expressed as $P(y)=\sum_{k=0}^{N-1} C_{k}^{N-1+k y^{k}}$, where $C_{k}^{N-1+k}$ is binomial coefficient.

\section{B. Data and Filtering}

The article collected data of 6 stock indices between January 10th, 2006 and April 30th, 2008, they are SHCI (Shanghai Composite Index), SZCI (Shenzhen Component Index), HIS (Heng Seng Index), N225, Dow-Jones, and FTSE100 (all data are close price, you can get the data from http://finance.yahoo.com ). These data are used to measure the volatility of stock markets of Shanghai, Shenzhen, Hong 
Kong, Tokyo, New York and London, which are the world's 6 biggest finance centers (Table 1). Because different markets close at different dates, so we just use data when all the 6 markets are opening. First, take logarithm of all indices; then use Daubechies wavelet filter to separate low frequency signal and high frequency noise in indices series from each other.

TABLE 1. TOTAL VALUE OF SHARE TRADING AND NUMBER OF LISTED COMPANIES IN THE SIX EXCHANGES

\begin{tabular}{|c|c|c|c|c|}
\hline \multirow{2}{*}{ Exchange } & \multicolumn{2}{|c|}{$\begin{array}{c}\text { Total value (USD } \\
\text { billion ) }\end{array}$} & \multicolumn{2}{c|}{$\begin{array}{c}\text { No. of listed } \\
\text { companies }\end{array}$} \\
\cline { 2 - 5 } & 2008 & 2007 & 2008 & 2007 \\
\hline Shanghai & 2600.2 & 4028.6 & 864 & 860 \\
\hline Shenzhen & 1248.7 & 2046 & 740 & 670 \\
\hline $\begin{array}{c}\text { Hong } \\
\text { Kong }\end{array}$ & 1629.8 & 2129.8 & 1261 & 1241 \\
\hline Tokyo & 5607.3 & 6409.9 & 2390 & 2414 \\
\hline $\begin{array}{c}\text { NYSE } \\
\text { (US) }\end{array}$ & 33638.9 & 26625 & 3011 & 2297 \\
\hline London & 6271.5 & 6056.5 & 3096 & 3307 \\
\hline
\end{tabular}

Notes: The data in table 1 comes from world federation of exchanges' Annual Report 2008 (http://www.world-exchanges.org).

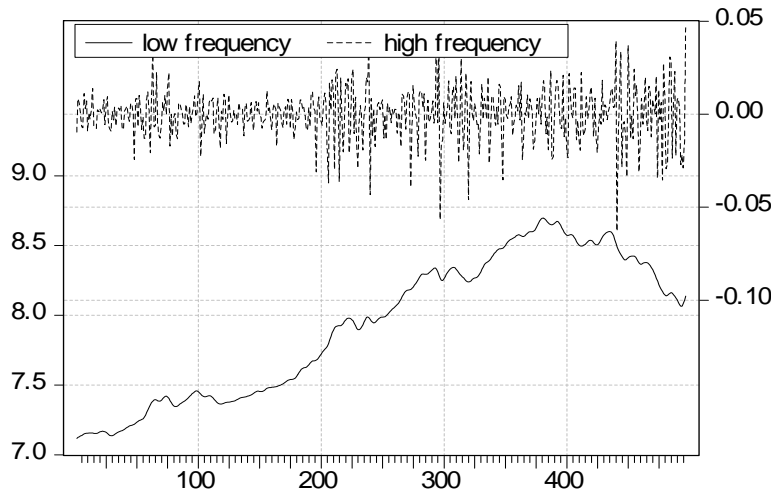

Figure 1. Shanghai Composite Index

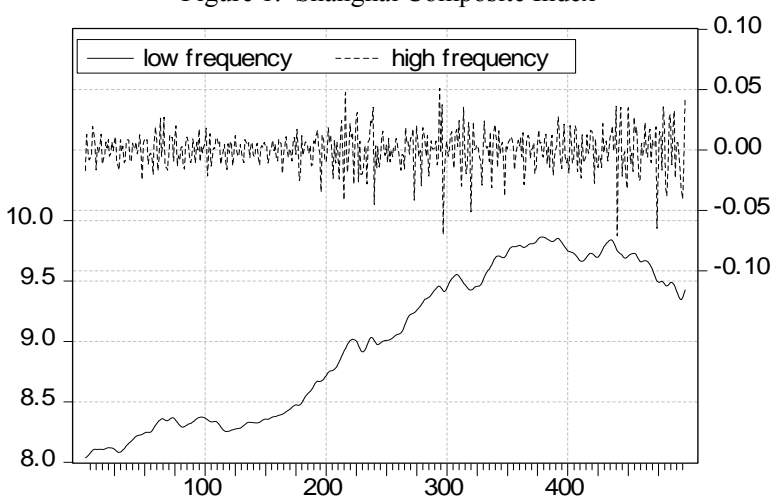

Figure 2. Shenzhen Component Index

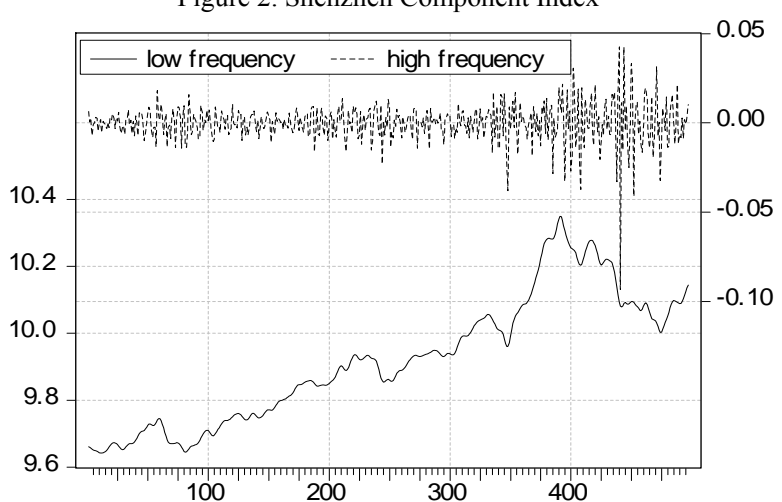

Figure 3. Heng Seng Index
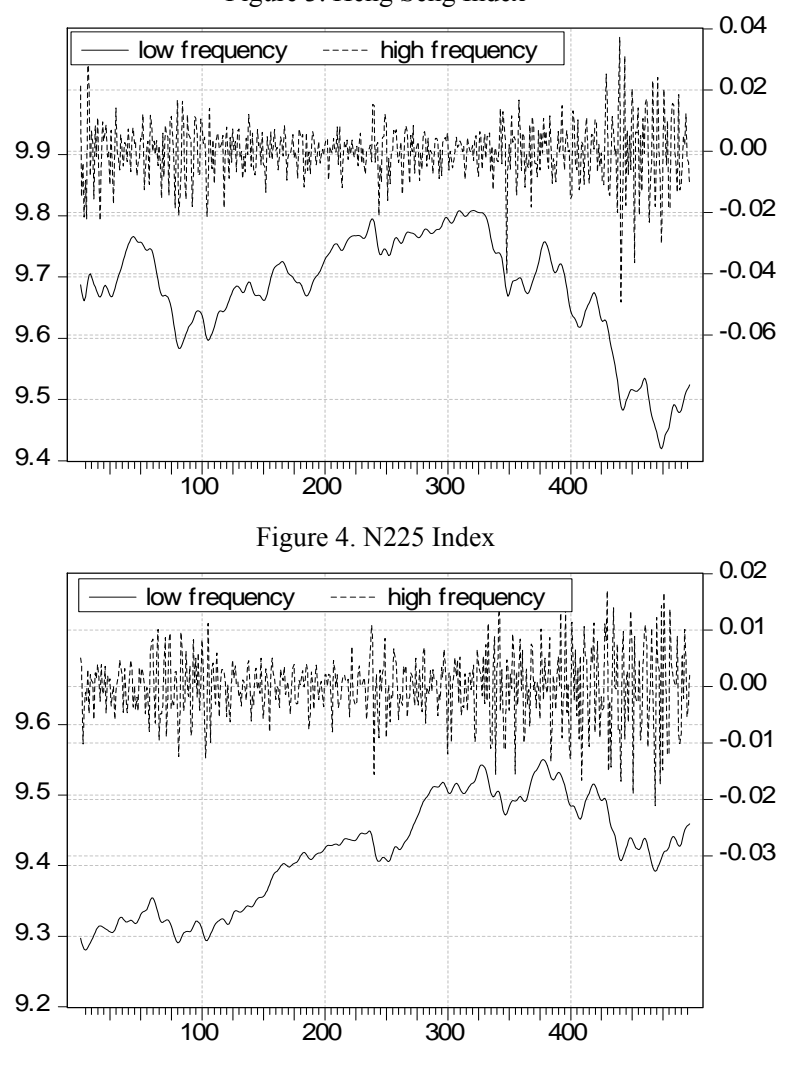

Figure 5. Dow-Jones Index

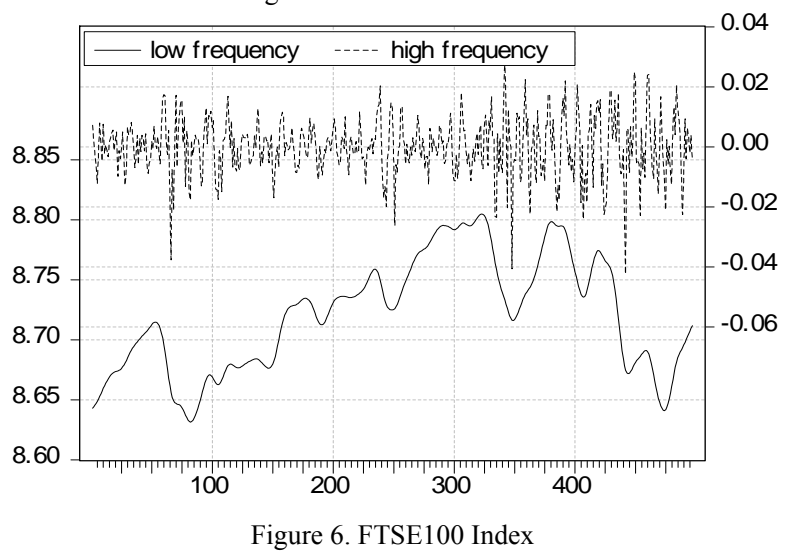

\section{ESTIMATION AND SIMULATION}

The article uses low frequency signal to estimate parameters of SVAR. Seeing from figures after filtering, volatility of Chinese stock market has evident intercept, so we should retain constant term in the model. According to Schwarz's criterion, we choose 3 as the lag length. Table 2 is the estimation results of Shanghai stock market. In table 2, $X_{1}$ denotes Shanghai stock index; $\mathrm{X}_{2}$, Shenzhen index; $\mathrm{X}_{3}$, Heng Seng index; $\mathrm{X}_{4}, \mathrm{~N} 225$ index; $\mathrm{X}_{5}$, Dow-Jones index; $\mathrm{X}_{6}$, FTSE100 index. In addition the constant term in model is -0.08 , which have passed the T test already.

Parameters in table 2 show that Shanghai stock market is not influenced significantly by Shenzhen and Tokyo stock markets; less affected by Hong Kong stock market but significantly influenced by New York and London stock markets. The closing price of Shanghai stock market can increase by $0.22 \%$ when the closing price of New York stock market increases by $1 \%$ while lag length is 1 ; closing price of 
the former will decrease by $0.44 \%$ when that of the latter increases by $1 \%$ while lag length is 2 ; closing price of the former can increase by $0.25 \%$ when that of the latter increases by $1 \%$ while lag length is 3 . The closing price of Shanghai stock market will decrease by $0.46 \%$ when the closing price of London stock market increases by $1 \%$ while lag length is 1 ; closing price of the former can increase by $0.97 \%$ when that of the latter increases by $1 \%$ while lag length is 2 ; closing price of the former will decrease by $0.54 \%$ when that of the latter increases by $1 \%$ while lag length is 3. Volatility of Shanghai stock market is similar to that of New York but opposite to that of London.

TABLE 2. ESTIMATION RESULTS OF SVAR MODEL

\begin{tabular}{|c|c|c|c|c|c|}
\hline $\mathrm{X}_{1}(-1)$ & $\mathrm{X}_{1}(-2)$ & $\mathrm{X}_{1}(-3)$ & $\mathrm{X}_{2}(-1)$ & $\mathrm{X}_{2}(-2)$ & $\mathrm{X}_{2}(-3)$ \\
\hline $2.67^{* * *}$ & $-2.51^{* * *}$ & $0.83^{* * *}$ & 0.02 & -0.04 & 0.02 \\
\hline$(54.33)$ & $(-26.05)$ & $(16.77)$ & $(0.46)$ & $(-0.55)$ & $(0.56)$ \\
\hline $\mathrm{X}_{3}(-1)$ & $\mathrm{X}_{3}(-2)$ & $\mathrm{X}_{3}(-3)$ & $\mathrm{X}_{4}(-1)$ & $\mathrm{X}_{4}(-2)$ & $\mathrm{X}_{4}(-3)$ \\
\hline $0.07^{*}$ & $-0.13^{*}$ & $0.06^{*}$ & -0.01 & 0.02 & 0.01 \\
\hline$(1.43)$ & $(-1.44)$ & $(1.36)$ & $(-0.26)$ & $(0.16)$ & $(0.09)$ \\
\hline $\mathrm{X}_{5}(-1)$ & $\mathrm{X}_{5}(-2)$ & $\mathrm{X}_{5}(-3)$ & $\mathrm{X}_{6}(-1)$ & $\mathrm{X}_{6}(-2)$ & $\mathrm{X}_{6}(-3)$ \\
\hline $0.22^{* *}$ & $-0.44^{* * *}$ & $0.25^{* * *}$ & $-0.46^{*}$ & $0.97^{*}$ & $-0.54^{* *}$ \\
\hline$(2.74)$ & $(-2.93)$ & $(3.20)$ & $(-1.89)$ & $(2.06)$ & $(-2.27)$ \\
\hline
\end{tabular}

Notes: parameters are marked with asterisk. Numbers in bracket are T test value. $* * *$ denotes significance at 1 percent level; $* *$ denotes significance at 5 percent level; * denotes significance at 10 percent level; numbers with no asterisk mean they don't pass $\mathrm{T}$ test.

\section{A. Impulse Response}

The article use impulse response to analyze the degree of Shanghai stock market affected by foreign stock markets. Harvey and Mills (2002) pointed out that impulse response don't change with variable order, he also comprehensively considered correlative historical patterns which were observed at different shock time. The article use Cholesky decomposition to make error term orthogonal. Impulse response measures the effect of innovation shock which is equal to unit standard deviation on the current and future value of endogenous variable. The following is the response of Shanghai stock market after shocked by volatility of foreign stock markets.

Curves in Figure.7-9 are simulation for impulse response function, lateral axis denotes lag length, and longitudinal axis denotes response degree for innovation shock. Solid line denotes value of simulation, dashed line denotes confidence interval of 2 times standard deviation. Impulse curves show that volatility shock of Shanghai stock market got from Tokyo stock market is small while that got from New York and London stock markets is significant.

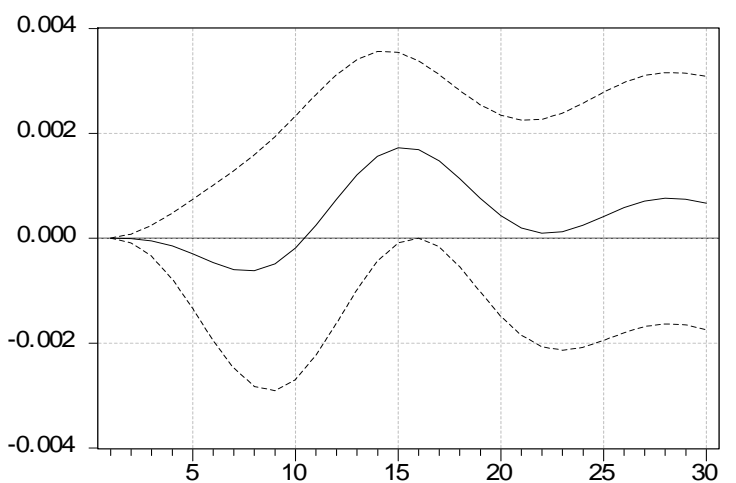

Figure 7. response of Chinese stock market to Japanese stock market

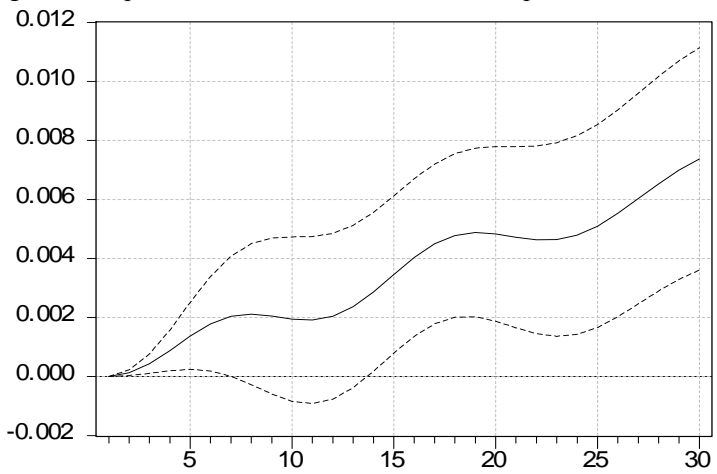

Figure 8. response of Chinese stock market to American stock market

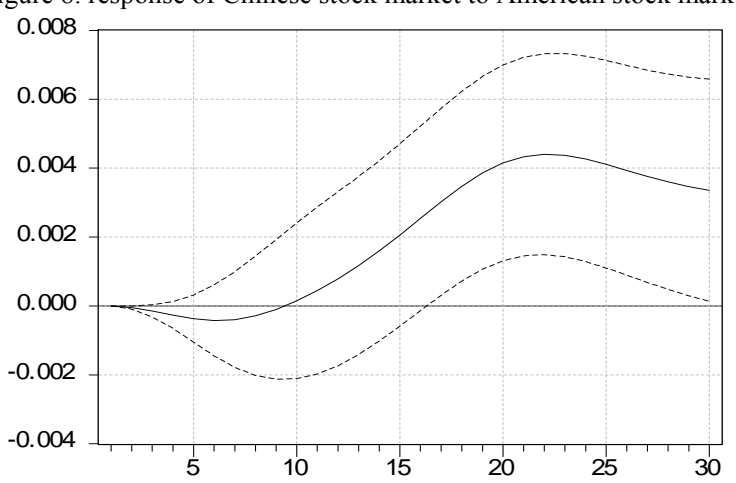

Figure 9. response of Shanghai stock market to British stock market

\section{B. Variance Decomposition}

By analyzing contribution rate of each structural shock to changes of endogenous variable, variance decomposition can further evaluate the importance of different structural shocks. Table 3 show that contribution rate of variance decomposition in Shanghai stock market is mainly determined by its own tendency. When observation period is 5 days, $2 \%$ volatility of Shanghai stock market is explained by other stock markets' volatility; as well as, $25 \%$ is explained by other stock markets when observation period is 30 days.

TABLE 3. RESULTS OF VARIANCE DECOMPOSITION contribution rate of variance decomposition

\begin{tabular}{lllllll} 
No. & $\mathrm{x}_{1}$ & $\mathrm{x}_{2}$ & $\mathrm{x}_{3}$ & $\mathrm{x}_{4}$ & $\mathrm{x}_{5}$ & $\mathrm{x}_{6}$ \\
\hline 1 & $100.00 \%$ & $0.00 \%$ & $0.00 \%$ & $0.00 \%$ & $0.00 \%$ & $0.00 \%$ \\
2 & $99.90 \%$ & $0.00 \%$ & $0.02 \%$ & $0.00 \%$ & $0.07 \%$ & $0.01 \%$ \\
3 & $99.68 \%$ & $0.00 \%$ & $0.07 \%$ & $0.00 \%$ & $0.22 \%$ & $0.03 \%$ \\
7 & $98.70 \%$ & $0.00 \%$ & $0.13 \%$ & $0.07 \%$ & $1.04 \%$ & $0.06 \%$ \\
12 & $97.76 \%$ & $0.22 \%$ & $0.10 \%$ & $0.11 \%$ & $1.72 \%$ & $0.09 \%$ \\
13 & $97.26 \%$ & $0.31 \%$ & $0.10 \%$ & $0.19 \%$ & $1.99 \%$ & $0.16 \%$
\end{tabular}




\begin{tabular}{lllllll}
14 & $96.51 \%$ & $0.40 \%$ & $0.10 \%$ & $0.32 \%$ & $2.38 \%$ & $0.29 \%$ \\
16 & $94.26 \%$ & $0.51 \%$ & $0.11 \%$ & $0.60 \%$ & $3.70 \%$ & $0.82 \%$ \\
18 & $91.36 \%$ & $0.53 \%$ & $0.16 \%$ & $0.72 \%$ & $5.46 \%$ & $1.76 \%$ \\
19 & $89.92 \%$ & $0.52 \%$ & $0.20 \%$ & $0.71 \%$ & $6.29 \%$ & $2.36 \%$ \\
23 & $85.15 \%$ & $0.57 \%$ & $0.36 \%$ & $0.60 \%$ & $8.56 \%$ & $4.76 \%$ \\
25 & $82.77 \%$ & $0.87 \%$ & $0.45 \%$ & $0.57 \%$ & $9.69 \%$ & $5.66 \%$ \\
26 & $81.39 \%$ & $1.12 \%$ & $0.50 \%$ & $0.56 \%$ & $10.42 \%$ & $6.01 \%$ \\
29 & $76.61 \%$ & $1.92 \%$ & $0.79 \%$ & $0.56 \%$ & $13.44 \%$ & $6.68 \%$ \\
30 & $74.96 \%$ & $2.11 \%$ & $0.92 \%$ & $0.56 \%$ & $14.64 \%$ & $6.81 \%$ \\
\hline
\end{tabular}

\section{DISCUSSIONS AND CONCLUSIONS}

As Chinese stock market has been deregulated by China's Securities Regulatory Commission, Chinese stock markets are becoming more and more mature and open, which are integrated into the global stock market gradually. At present, the B-share market has opened to Chinese mainland investors and the A-share market has opened to foreign investors. Chinese stock market is trending toward integration and globalization, which can be known from the response of Shanghai Composite Index shocked by Dow-Jones Index and FTSE100 Index. In all the mature stock indices in the paper, influence of Dow-Jones Index on Shanghai Composite Index is most significant, followed by FTSE100 Index. There are several reasons as follows.

First, market scale of NYSE Euonext and London SE are larger. According to the ranking of total value of share trading in 2008, NYSE Euonext ranks second, followed by London SE and Tokyo SE in turn. Shanghai SE, Hong Kong SE and Shenzhen SE rank seventh, tenth and fifteenth respectively.

Second, many Chinese companies have been listed in NYSE Euonext and London SE. London SE owns the largest number of foreign listed companies, followed by NYSE Euonext. There are 681 foreign companies trading their shares in London SE and 415 in NYSE Euonext in 2008. Foreign listed companies in Tokyo SE are 16 and these in Hong Kong SE are 10. Up to March 2009, there are 66 Chinese companies listed in NYSE Euonext and 36 in London SE.

Third, global financial crisis aroused from America has strengthened the linkage between American stock market and that of other country. The 2007-2008 financial crises make stock index of stock markets of America and other countries show the same tendency. Just as table 3 shows, comparing with impacts of other indices, Dow-Jones Index has the greatest impact on SHCI.

Fourth, there is a time difference between Shanghai stock market and stock market in New York and London. Therefore, there is enough time for price fluctuation on the later markets to be spread to the former one. The influence of Hong Kong HIS to Shanghai Composite Index is relatively weaker, which is in accord with the conclusion of Wang and Gan (2008). Co-integration test shows Hong Kong stock market and Chinese mainland stock market are still two relatively independent markets (Wang and Gan, 2008). There are no obvious information transmission between Hong Kong stock market and Chinese mainland stock market.
Financial crisis in 2008 influenced worldwide stock markets. The total value of share trading in major Stock Exchanges is declined more or less. The total value of share trading in Shanghai SE declined by $41.0 \%$, in Shenzhen SE declined by $44.2 \%$, in Hong Kong SE declined by $23.8 \%$, in Taiwan SE declined by $21.1 \%$, in Tokyo SE declined by $23.4 \%$ and in London SE declined by $33.0 \%$. Comparing to 2007, we find, the total value of share trading in NYSE Euonext and NASDAQ OMX in 2008 are increased by $15.5 \%$ and $29.6 \%$ respectively, despite losing 65 and 112 listing companies respectively. Why does not the total value of share trading in the country which is seriously impacted by financial crisis decline? The reasons should be shed light on in the follow-up researches.

\section{REFERENCES}

[1] W. Bailey, "Risk and Return on China New Stock Market: Some Preliminary Evidence," Pacific-Basin Finance Journal. 1994, 2(1), pp.243-260.

[2] R. Johnson, M. Sun, L. Soenen, "The Shenzhen Stock Exchange: an Assessment of the Risk and Return," Asian Business. 1994, 10(4), pp.1-16.

[3] B. N. Huang, C. W. Yang, J. W. Hu, "Causality and Co-integration of Stock Markets among the United States, Japan, and the South China Growth Triangle," International Review of Financial Analysis. 2000, 9(3), pp.281-297.

[4] J. A. Tan, "Contagion Effects during the Asian Financial Crisis: Some Evidence from Stock Price Data," Pacific Basin Working Papers Series, 1998, No.98-06, pp.98-106.

[5] T. Y. Chang, C. Nieh, "International Transmission of Stock Price Movements among Taiwan and Its Trading Partners: Hong Kong, Japan and the United States," Review of Pacific Basin Financial Markets and Policies. 2001, 4(4), pp.379-401.

[6] E. D. Roca, "Short-term and Long- term Price Linkages between the Equity Markets of Australia and Its Major Trading Partners," Applied Financial Economics. 1999, 9(5), pp.501-511.

[7] A. C. Worthington, M. Katsuura, H. Higgs, "Price Linkages in Asian Equity Markets: Evidence Bordering the Asian Economic, Currency and Financial Crises," Asia-Pacific Financial Markets. 2003, 10 (1), pp. $29-44$.

[8] S. Edwards, J. G. Biscarri, F. P. Gracia. "Stock Market Cycles, Financial Liberalization and Volatility," Journal of International Money and Finance. 2003, 22(7), pp.925 -955.

[9] S. N. Wang, Y. H. Pan, "Study on Interlinkage between US and China Stock Markets," Journal of Zhejiang University (Engineering Science). 2004, 38(11), pp.1431-1435.

[10] K. M. Wang, T. N. Thi, "Does Contagion Effect Exist Between Stock Markets of Thailand and Chinese Economic Area (CEA) during the 'Asian Flu?'" Asian Journal of Management and Humanity Sciences. 2006, 1(1), pp.16-36.

[11] H. J. Abdulnasser, E. Roca, D. Buncic, "Bootstrap Causality Tests of the Relationship between the Equity Markets of the U.S. and other Developed Countries: Pre- and Post-September 11," Journal of Applied Business Research. 2006, 22(3), pp.65-74.

[12] A. Hasan, H. M. N. Saleem, M. S. Abdullah, "Long-Run Relationships between an Emerging Equity Market and Equity Markets of the Developed World an Empirical Analysis of Karachi Stock Exchange,' International Research Journal of Finance and Economics. 2008, 16, pp.52-62.

[13] Y. Zhao, Y. Zhang, C. J. Qi, "Analysis on Price Fluctuation of Horticulture Products Based on DWT and SVAR," IEEE International Symposium on Knowledge Acquisition and Modeling, Wuhan, 2008, pp.166-171.

[14] Y. Zhao, Y. Zhang, C. J. Qi, "Transaction Behavior and Volatility of Price Signals in Futures Market," The $2^{\text {nd }}$ International Symposium on Electronic Commerce and Security, Nanchang, 2009, pp.79-83.

[15] D. I. Harvey, T. C. Mills, "Unit Roots and Double Smooth Transitions," Journal of Applied Statistics. 2002, 29(5), pp.675 -683.

[16] Y. G. Wang, D. S. Gan, (2008). “An Economic and Empirical Analysis of Hong Kong Equity Market's Co-movements with The Global Markets," Asian-Pacific Economics. 2008, 25(4), pp.106-110. 
Yu Zhao (Xinji City, Hebei, P.R.C., 10-11-1982) got his $\mathrm{PhD}$ in Management from Huazhong Agricultural University, Wuhan, Hubei, and P.R.C. He earned his Doctor's degree in 2010. His major fields of study are risk management, intelligence computation, and supply chain management, etc.

$\mathrm{He}$ is involved in the Program for New Century Excellent Talents in University (NCET050671) supported by Ministry of Education, National Social Science Fund (02CJY026, 06BJY088, 08CJY045). His major publications in 2009 are as follows, Game Countermeasures on Trade Barriers of Chinese Horticultural Exports, Beijing, Science Press, 2009. His research interests are intelligence computation and modeling techniques.

Dr. Zhao is an honorary president of Huazhong Agricultural University Mathematical Modeling Association. 